\title{
Processamento de achocolatado de cupuaçu por spray-dryer
}

\author{
Suzana Caetano da Silva Lannes*, Magda Leite Medeiros \\ Departamento de Tecnologia Bioquímico-Farmacêutica, Faculdade de Ciências Farmacêuticas, \\ Universidade de São Paulo
}

*Correspondência:

S.C.S.Lannes

Departamento de Tecnologia

Bioquímico-Farmacêutica

FCF/USP

Av.Prof.Lineu Prestes, 580 - Bloco 16

Cid.Universitária

05508-900 - São Paulo-SP - Brasil

E-mail: scslan@usp.br
O achocolatado de cupuaçu é uma mistura do pó de cupuaçu, açúcar, aroma e outros ingredientes constantes da formulação. Este produto formulado foi processado por spray-dryer, gerando um produto seco, pulverizado e instantaneizado. O achocolatado acrescido de água (concentrado) passa pelo spray-dryer formando glóbulos de pequeno diâmetro que são arrastados por uma corrente de ar quente. A rápida evaporação de líquido permite manter baixa a temperatura do ar na secagem, não afetando o produto. O pó de cupuaçu não dispersa prontamente em água devido ao seu conteúdo de óleo. Conseqüentemente, necessita-se de uma forma desengordurada para se obter instantaneização. A secagem por spray-dryer reúne as melhores condições de rendimento técnico em comparação com outros processos. Obtiveram rendimentos de processo acima de $20 \%$ e a instantaneização completa do produto.
Unitermos:

- Cupuaçu

- Achocolatado

- Spray-dryer

- Instantaneização

\section{INTRODUÇÃO}

O cupuaçuzeiro (Theobrama grandiflorum) é uma das fruteiras mais populares da Amazônia e vem sendo implantada comercialmente na região sudeste da Bahia. O seu fruto mede de 12 a $15 \mathrm{~cm}$ de comprimento e 10 a 12 $\mathrm{cm}$ de diâmetro, com peso médio de $1 \mathrm{~kg}, 30 \%$ de polpa e 35 sementes. A polpa pode ser utilizada para confecção de sorvetes, sucos, geléias, doces e iogurtes e as sementes, para fabricação de chocolate branco, ao leite e meio amargo, considerados de ótima qualidade. Atualmente, o cupuaçu vem conquistando o mercado de outras regiões do país e do exterior. Espécie de boa adaptação à sombra, propicia a formação de consórcios com outras plantas de porte florestal, permitindo bons resultados econômicos e ecológicos. É uma fruta tropical com grande potencialidade agroeconômica para a região sudeste da Bahia, propiciando um adicional de renda integrado com o cacau e outros cultivos tropicais (Venturieri, Aguiar, 1988; Nazaré et al., 1990; Venturieri, 1993; Wolf, 1997; Medeiros, Lannes, 1999).

O pó de cupuaçu, assim como o cacau em pó, podem ser obtidos a partir da pasta do produto preparada com sementes torradas, que podem ser ou não alcalinizadas (sem solubilizar). Para poder obter o pó, a pasta é previamente desengordurada. A torta pode ser obtida por filtroprensa horizontal e, em seguida, triturada em moinho de disco-dentado (Beckett, 1994; Medeiros, Lannes, 1999; Lannes, Medeiros, 2002).

O grande trunfo para colocação do chocolate de cupuaçu no mercado é a possibilidade ímpar de se ofertar um produto regional, de alta qualidade e baixo custo, criando interessante alternativa de consumo. Ainda, o сириас̧и em pó possui baixos valores de teobromina $(0,06 \%)$ com relação ao cacau ( $15 \%$ do conteúdo do cacau). Os valores de teobromina encontrados para a torta de 
cacau são os mesmos encontrados no chocolate meio amargo (Amazonas, 1995; Medeiros, Lannes, 1999; Lannes, Medeiros, 2002).

Os processos de produção dos produtos de cupuaçu (manteiga de cupuaçu e torta) seguem os fluxogramas a seguir (Figuras 1 e 2) (Amazonas, 1995).

O chocolate em pó obedece os passos iniciais dos produtos anteriores, até o segundo estágio de prensagem. Na continuação, apresenta-se fluxograma da Figura 2.

A tecnologia spray-drying (a mesma nomenclatura utilizada no Brasil) é muito utilizada em diversos segmentos industriais, incluindo o farmacêutico e o alimentício. Embora seja uma tecnologia que necessita de altos investimentos em instalações e operação, muitas são as razões pelas quais a mesma é muito utilizada. Estas vantagens incluem a produção de partículas de qualidade consistente, a facilidade em relação ao uso contínuo, a aplicabilidade da técnica em materiais termossensíveis e termorresistentes, a capacidade de processar diversos tipos de matérias-primas e a flexibilidade para a definição de um projeto com base na formulação. Para fazer uso dessas vantagens, existem diversos aspectos que devem ser considerados. Dentre eles estão a avaliação da formulação e dos parâmetros de processo, o tipo específico de partícula a ser produzida e as propriedades do material utilizado (Wendel, Celik, 1998).

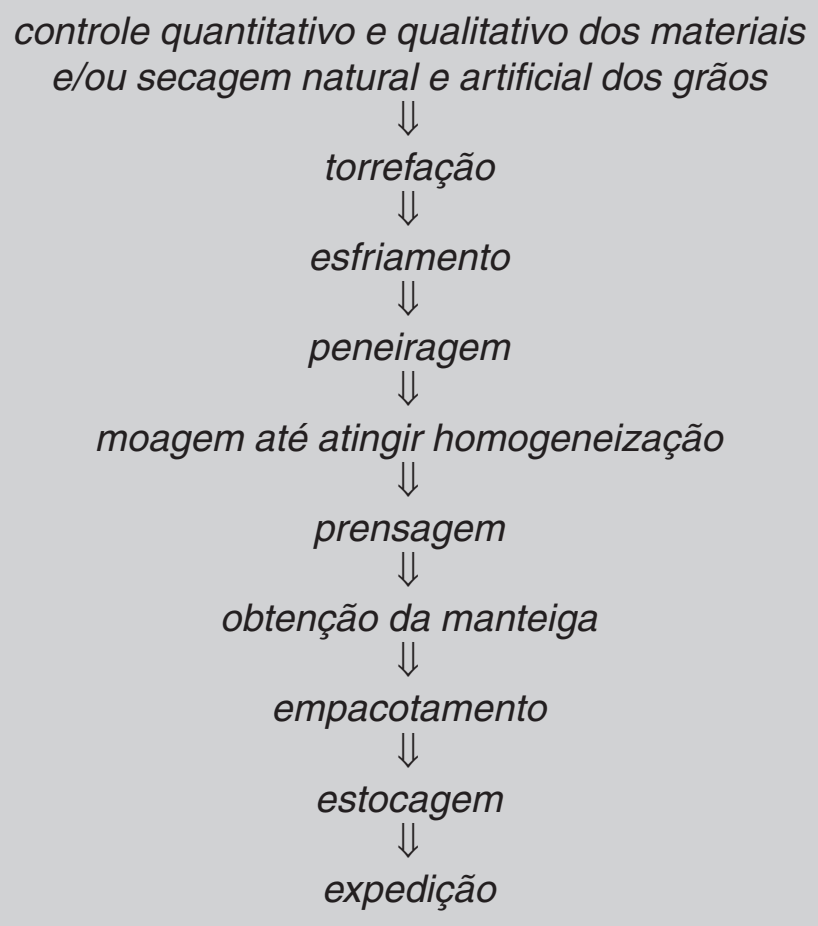

FIGURA 1 - Fluxograma de obtenção da manteiga de cupuaçu e torta.
Secagem por nebulização é a transformação de líquidos de baixa ou alta viscosidade, mesmo aqueles que são quase pastosos, em produto seco e pulverizado em uma única operação. O líquido ou pasta são atomizados usando-se um sistema centrífugo ou de alta pressão, onde as gotículas atomizadas imediatamente entram em contato com um fluxo de ar quente. A rápida evaporação permite manter baixa a temperatura do produto. A transferência de calor e de massa são realizadas pelo contato direto entre o gás quente e as gotículas dispersas. As partículas finas são separadas do gás em ciclones externos ou em mangas coletoras. Quando apenas se deseja a fração grossa do produto acabado, os finos podem ser recuperados em lavadores; o líquido do lavador é concentrado e retorna ao secador (McCabe, Smith, 1956; Masters, 1976; Linoya et al., 1991; Van't Land, 1991).

O uso principal dos secadores a pulverização é na secagem comum de soluções e de suspensões aquosas. São também usados nas operações combinadas de secagem e de tratamento térmico. A alimentação é usualmente uma solução líquida, uma suspensão ou uma pasta que pode ser pulverizada (Perry, Chilton, 1980). O produto a ser seco passa por bicos de tamanhos que podem variar, influenciando no tamanho das partículas obtidas e a parte líquida é transformada num spray atomizado. O pó é carregado numa corrente de ar, que o transporta em contato com o spray.

A otimização das características físicas e químicas dos materiais utilizados nessa técnica envolve geralmente a comparação entre parâmetros de processo, tais como aquecimento, volume de ar, tipo de bico atomizador, vazão do material a ser seco ou do sistema de atomização e

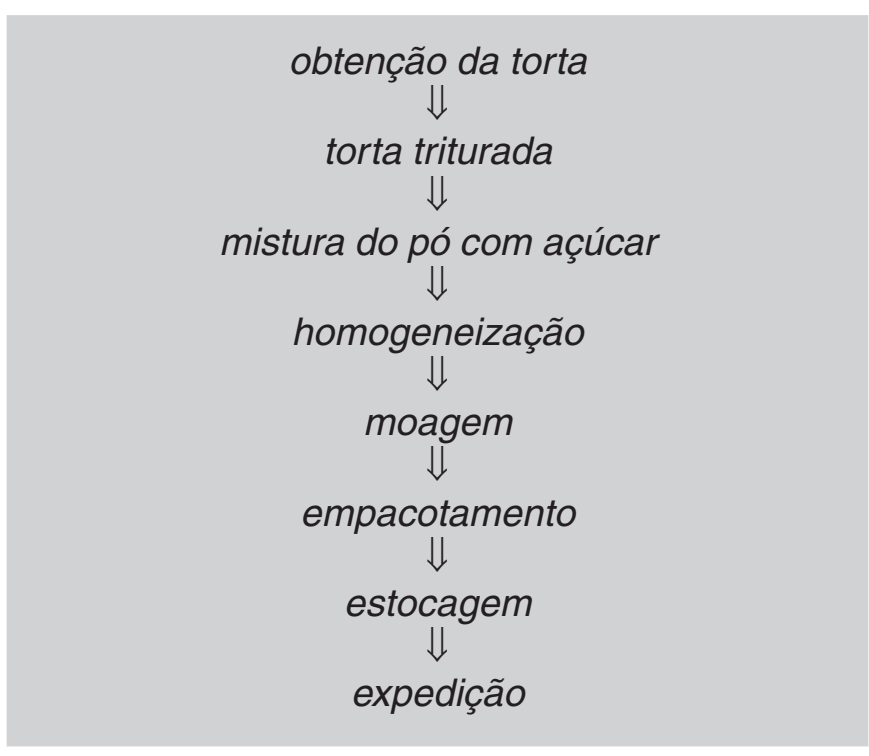

FIGURA 2 - Fluxograma de obtenção do chocolate em pó. 
temperatura do ar de secagem. Os parâmetros de formulação são avaliados conjuntamente com os de processo. É importante se verificar, por exemplo, quando se eleva a temperatura, se não existe extensa denaturação protéica, perda de aromas e flavorizantes, assim como comprometimento da solubilidade, estabilidade e compactação (Wendel, Celik, 1998; Rhodes, 1990).

$\mathrm{O}$ aquecimento e a transferência de massa durante a secagem ocorrem com filmes de ar e vapor ao redor das gotículas. Esta proteção do vapor mantém a partícula na temperatura de saturação. Como a partícula não se torna seca, a evaporação continua acontecendo e a temperatura dos sólidos não se aproxima da temperatura da saída da secagem. Devido a isto, produtos sensíveis podem ser secos em temperaturas relativamente altas.

O formato da maior parte das partículas atomizadas é esférico, que garante fluxo como o de fluidos. Isto auxilia no processo de manuseio e envase, por exemplo, e também na diminuição de custos. As partículas possuem, ainda, homogeneidade na composição e a distribuição no tamanho das partículas é muito próxima, minimizando a obtenção de partículas muito finas, o que é muito importante para o produto obtido.

Fatores como umidade e atividade de água são de grande importância no estudo do produto obtido. A definição do processo e a adequação dos parâmetros de operação do equipamento são particulares a cada produto final desejado, em função das características que se deseja a ele imprimir (Straatsma et al., 1999a).

Sendo a técnica spray-dryer amplamente utilizada na indústria, o estudo de sua potencialidade e adequação para obtenção de produtos como o chocolate de cupuaçu em pó é maneira de se estudar o processo de secagem tanto para este como para outros produtos e, ainda, de se explorar o equipamento e seus recursos, obtendo-se um produto diferenciado. A instantaneização e melhoria da molhabilidade do produto são fatores muito importantes na obtenção de um produto em pó de cupuaçu, em que a técnica de secagem vem a ser um meio para obtenção destas características. Straatsma et al. (1999b) estudaram o índice de solubilidade de materiais instantaneizados por spraydryer, sendo que este índice é de importância primária para pós instantaneizados. A carga térmica de produtos alimentícios durante a secagem é um fator importante para a qualidade final do pó, pois a exposição ao calor pode levar à formação de materiais insolúveis, que são indesejáveis especialmente para pós instantâneos.

O chocolate de cupuaçu ainda é um produto pouco explorado, sendo seu estudo de grande interesse para a futura industrialização e comercialização.

Os objetivos deste trabalho foram formular produ- tos tipo achocolatado, com substituição do cacau em pó pelo cupuaçu, normal com e sem adição de cálcio e dietético, e processar o produto formulado em equipamento spray-dryer para promover instantaneização.

\section{MATERIAL E MÉTODOS}

\section{Material}

O pó de cupuaçu não lecitinado e não alcalinizado foi fornecido pela empresa CHOCAM, cujo processo de fabricação é descrito abaixo (Figura 3):

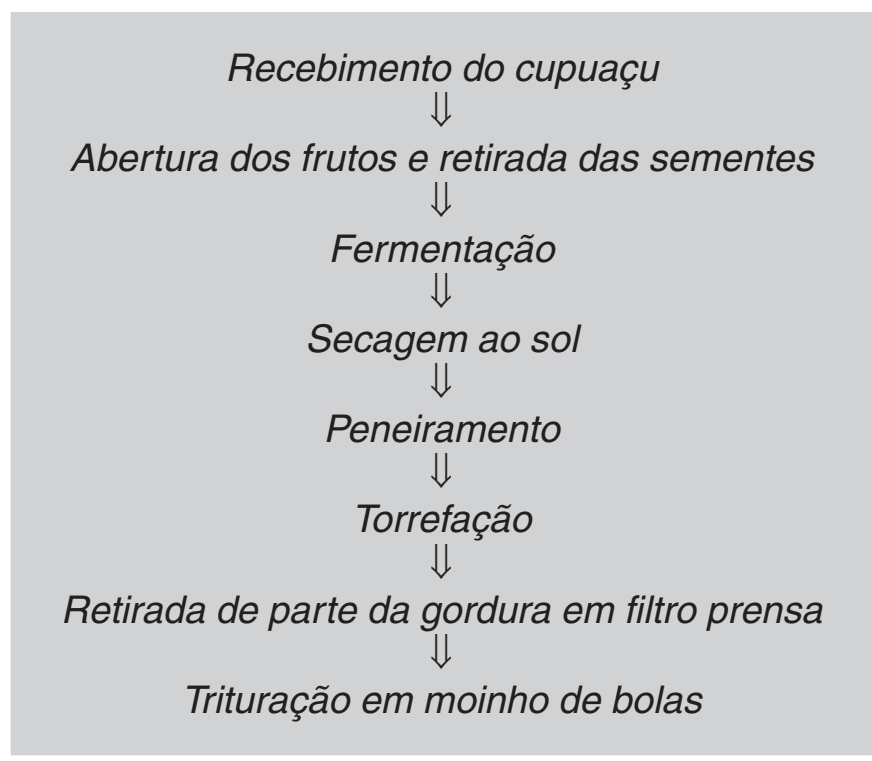

FIGURA 3 - Fluxograma de obtenção do pó de cupuaçu não lecitinado e não alcalinizado.

Outros produtos utilizados nas formulações:

- Soro de leite: Interseller Comércio Internacional Ltda.

- Extrato de malte: Novartis Nutrition S/A

- Aroma: aroma em pó natural de cacau com baunilha Duas Rodas ( 82-162-01-1)

- Celulose microcristalina com cálcio Avicel-plus ${ }^{\mathrm{TM}} \mathrm{CF}$ 3619: FMC Corporation

- Aspartamo em pó: Monsanto

- Leite em pó desnatado: Mocóca

\section{Métodos}

\section{Distribuição e tamanho de partículas}

Para essa análise utilizou-se a técnica de difração de raio laser. O princípio dessa técnica é passar a amostra (meio aquoso), utilizando água desionizada, por feixes de raio laser, que emite uma vibração para cada intervalo de 
tamanho da partícula. O equipamento utilizado foi o Mastersizer S Long Bed Ver. 2.19, marca MALVERN.

Extração e determinação do teor de lipídios totais

A extração e determinação foram feitas com $10 \mathrm{~g}$ de produto moído, tratado previamente com $75 \mathrm{~mL}$ de ácido clorídrico concentrado (37\%) e $200 \mathrm{~mL}$ de água destilada, deixado em fervura durante $20 \mathrm{~min}$, filtrado com $3 \mathrm{~L}$ de água fervente e seco em estufa no próprio papel de filtro por $12 \mathrm{~h} \mathrm{a} 75^{\circ} \mathrm{C}$. A extração da gordura é efetuada com éter de petróleo por aproximadamente $4 \mathrm{~h}$ em extrator de Soxhlet. O éter é evaporado após resfriamento e o produto é mantido em estufa a $100{ }^{\circ} \mathrm{C}$ por $1 \mathrm{~h}$. Após resfriamento em dessecador sob vácuo, proceder-se-á à pesagem. O tempo de secagem de $1 \mathrm{~h}$ deve ser suficiente para produzir peso constante (Schetty et al., 1969 - método 36 C/04).

\section{Proteína}

Efetuada seguindo-se a metodologia dos Métodos Analíticos do Instituto Adolfo Lutz, com equipamento Macro Kjeldahl (Instituto Adolfo Lutz, 1976).

Cinzas

Efetuada seguindo-se a metodologia dos Métodos Analíticos do Instituto Adolfo Lutz (Instituto Adolfo Lutz, 1976).

\section{Molhabilidade}

O teste foi efetuado utilizando-se Becker de $250 \mathrm{~mL}$, com $200 \mathrm{~mL}$ de água destilada. O pó foi adicionado à água cuidadosamente, a uma altura de $4 \mathrm{~cm}$ da superfície do líquido. Foi anotado o tempo em que todo o material era molhado (Engelhard Clays, s.d.).

Foi efetuado o teste para os produtos de cupuaçu em pó antes e após ser processado no spray-dryer.

\section{PARTE EXPERIMENTAL}

\section{Formulação}

As formulações desenvolvidas são mostradas na Tabela I, definidas por apresentarem melhor rendimento nos ensaios preliminares no spray-dryer.

Para formular o produto com celulose microcristalina adicionada de cálcio, adicionou-se $0,26 \%$ do produto na formulação após a instantaneização, no mesmo misturador na etapa inicial, por 15 minutos. No produto dietético, adicionou-se $0,7 \%$ do aspartamo em pó na formulação também após a instantaneização.

Para a formulação dietética, utilizou-se maltodextrina e leite em pó desnatado na formulação, pois houve a
TABELA I - Formulações dos produtos normal e dietético

\begin{tabular}{lcc}
\hline Ingrediente & Normal (\%) & Dietético (\%) \\
\hline Açúcar refinado & 53,4 & - \\
Pó de cupuaçu & 40,0 & 40,0 \\
Leite em pó desnatado & - & 34,5 \\
Maltodextrina & - & 20,4 \\
Soro de leite & 5,0 & 5,0 \\
Extrato de malte & 1,5 & - \\
Aroma & 1,0 & 1,0 \\
Sal refinado & 0,1 & 0,1 \\
\hline
\end{tabular}

retirada completa de açúcar da formulação. Assim, esses ingredientes auxiliaram no processo de secagem, fornecendo bom rendimento de processo.

O preparo das formulações seguiu o fluxograma abaixo (Figura 4):

Tamisação do pó de cupuaçu para separação de partículas maiores indesejáveis (maiores que $75 \mu \mathrm{m}$ )<smiles>[AlH]</smiles>

Pesagem dos ingredientes<smiles>[SiH2]</smiles>

Mistura dos ingredientes em misturador tipo tambor por $25 \mathrm{~min}$

FIGURA 4 - Fluxograma de obtenção das formulações.

\section{Instantaneização}

Foi utilizado equipamento mini spray-dryer Büchi190 (Figura 5), com largura/profundidade/altura = $50 \times 60 \times 100 \mathrm{~cm}$; peso $=48 \mathrm{~kg}$; máxima temperatura de secagem de ar $=220^{\circ} \mathrm{C}$. Máximo fluxo do ar de secagem é $45 \mathrm{~m}^{3}$. Opera com o princípio de bicos atomizadores em fluxo paralelo, sendo que o produto atomizado e o ar de secagem fluem na mesma direção. A capacidade máxima de evaporação é de $1 \mathrm{~L} / \mathrm{h}$ de líquido.

A ótima seleção da diferença das temperaturas de entrada e saída é um dos aspectos mais importantes do spray-dryer. A temperatura de saída não pode ser escolhida como desejada, sendo que resulta da combinação entre a temperatura de entrada - ajuste do aspirador e desempenho da bomba de alimentação do produto.

A alimentação do produto e a introdução do ar de secagem, nesse tipo de secador, se processa no topo da câmara em sistema de fluxo co-corrente. A secagem se processa enquanto o ar quente e o produto na forma de 


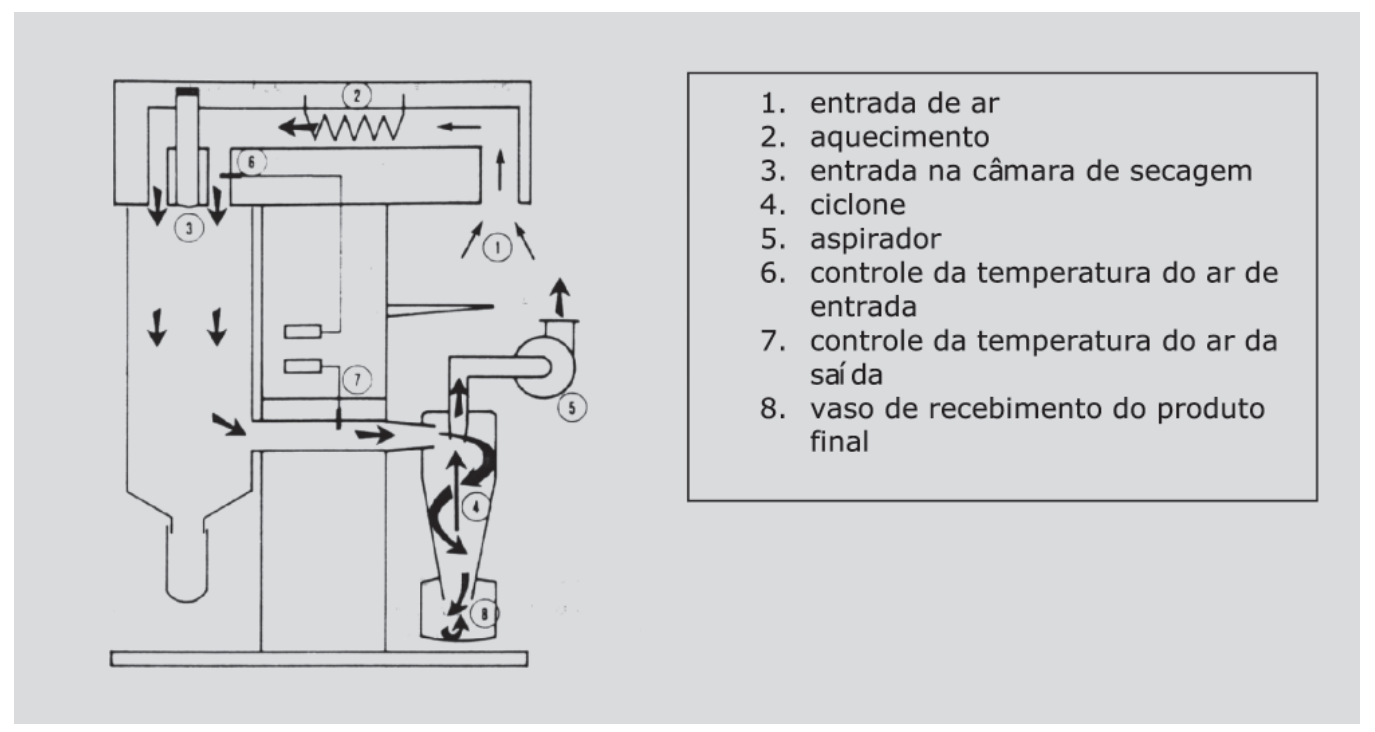

FIGURA 5 - Esquema do spray-dryer e do fluxo do ar de secagem

pequenas gotículas, percorrem a câmara de secagem até a sua base cônica. $\mathrm{O}$ ar úmido e produto seco vão em seguida ao ciclone, onde são separados, sendo o ar úmido retirado e o produto seco na forma de pó é coletado na base do ciclone.

Os spray-dryers promovem a secagem rápida de soluções, suspensões e substâncias pastosas, sendo obtido um produto seco e pulverizado. $\mathrm{O}$ achocolatado acrescido de água (concentrado) passa pelo spray-dryer formando glóbulos de pequeno diâmetro que são arrastados pela corrente de ar quente.

Foram ajustados os parâmetros de processo, formulação, concentração do produto a ser atomizado, temperaturas, velocidade de aspersão, objetivando-se obter maior rendimento. A Tabela II apresenta os parâmetros utilizados para processamento do produto normal e do dietético.
Para o produto normal o concentrado foi preparado com acréscimo de leite desnatado ( $30 \mathrm{~g}$ de leite em pó desnatado $+75 \mathrm{~mL}$ de água) e para o dietético foi acrescentada água.

\section{RESULTADOS E DISCUSSÃO}

A qualidade de alimentos em pó é baseada na variedade de propriedades que dependem de aplicações específicas. Em geral, o conteúdo de umidade final, a solubilidade, as propriedades reológicas do pó e a densidade são de primeira importância. Atualmente os principais desafios na produção de pós são o desenvolvimento de produtos e a redução de custo de processo. Por isso, a capacidade de produção das instalações disponíveis é maximizada, as condições de processo são direcionadas para mínimas perdas de produto, redução do consumo de energia, con-

TABELA II - Parâmetros de processo do spray-dryer para os produtos normal e dietético

\begin{tabular}{lcc}
\hline Parâmetros & Produto normal & Produto dietético \\
\hline Temperatura do concentrado $\left({ }^{\circ} \mathrm{C}\right)$ & 25 & 25 \\
Vazão de alimentação $(\mathrm{mL} / \mathrm{min})$ & 1,17 & 1,17 \\
Temperatura do ar de entrada $\left({ }^{\circ} \mathrm{C}\right)$ & 120 & 90 \\
Temperatura do ar de saída $\left({ }^{\circ} \mathrm{C}\right)$ & 92 & 70 \\
Temperatura do ar ambiente $\left({ }^{\circ} \mathrm{C}\right)$ & 25 & 25 \\
\% de sólidos na entrada $\left({ }^{\circ}\right.$ Brix $)$ & 41 & 41 \\
Tempo de operação do equipamento $(\mathrm{min})$ & 30 & 30 \\
Fluxo do spray $(\mathrm{L} / \mathrm{h})$ & 700 & 700 \\
Concentração $(\mathrm{g} / \mathrm{mL})$ & 1,0 & 0,6 \\
\hline
\end{tabular}


trole de qualidade on-line (Straatsma et al., 1999a; Omobuwajo et al., 2000).

A torta de cacau natural possui $\mathrm{pH}$ em torno de 5,05,3. Quando alcalinizada, este valor varia de 6,8-7,2. O сириас̧u em pó possui valor de 4,25 , bem próximo à torta de cacau natural, podendo ser alcalinizada para a produção do chocolate ou produto em pó de cupuaçu (Medeiros, Lannes, 1999).

\section{Instantaneização}

Uma forma de se obter produto em pó achocolatado com propriedades de instantaneização foi sugerida neste trabalho, com a utilização da técnica de spray-dryer, cujo efeito é melhorar a dispersão do produto em meio líquido. O rendimento de processo para os produtos esteve em torno de $20 \%$, sendo considerado bom para este tipo de equipamento que trabalha em escala piloto.

Cacau ou cupuaçu em pó não dispersam prontamente na água devido ao seu conteúdo de gordura. Conseqüentemente, o pó desengordurado é necessário para produzir bebida instantânea (Cartwright, 1981; Folkenberg et al., 1999; Gerhard et al., 1998, Guy, Vettel, 1975; Hough, Sanchez, 1998; Hough et al., 1997). O cupuaçu em pó utilizado nas formulações possuia $28,2 \%$ de gordura, sendo fornecido pela indústria desta forma, dificultando o processamento. Assim, acrescentou-se leite em pó desnatado no produto normal para obtenção do concentrado, a fim de melhorar a secagem.

A Tabela III apresenta os teores de lípidio, proteína e cinzas do achocolatado normal antes e após o processamento.

\section{Lipídios totais}

O teor de gordura na torta de cacau na indústria de chocolate varia de acordo com a indústria, e permanece em torno de 10-12\%. O pó de cupuaçu utilizado apresenta-se parcialmente desengordurado, com $28,15 \%$ de gordura (Medeiros, Lannes, 1999). O teor de lipídios interfere no processo de secagem por spray-dryer. Necessita-se de uma forma desengordurada para se obter instantaneização.
O teor lipídico do achocolatado normal antes do processamento era de $8,27 \%$ e após o processamento baixou para 3,22\% (Tabela III). Tal fato se observou pois foi acrescentado leite desnatado para formação do concentrado e houve um pouco de aderência de gordura na parede da câmara de secagem, diminuindo o teor de gordura e auxiliando na instantaneização do produto.

\section{Proteínas}

O cupuaçu em pó apresenta porcentagem de proteína ligeiramente maior que a de cacau. O produto em pó de сириас̧u possui teor bem menor devido à sua formulação. O pó de cupuaçu apresenta valor médio de proteína igual a $17,23 \%$, contra $14,72 \%$ encontrado no pó de cacau (Medeiros, Lannes, 1999). O produto formulado apresentado neste trabalho possui $9,24 \%$ de proteínas antes do processamento. $\mathrm{O}$ produto instantaneizado apresentou valor bem superior $(21,12 \%)$, devido ao conteúdo de leite acrescentado no preparo do concentrado para melhorar o processo de secagem (Tabela III). Neste caso, não se pode observar se o processamento por spray-dryer causou alteração nas proteínas, sendo que durante este processo podem ocorrer tais modificação (Wendel, Celik, 1998).

\section{Cinzas}

O conteúdo de cinzas é praticamente igual para os dois tipos de torta, próximo a 4\%, tanto para o pó de cacau como para o de cupuaçu (Medeiros, Lannes, 1999). Na indústria, a torta de cacau apresenta em torno de $7 \%$ de cinzas.

O teor de cinzas aumentou após instantaneização, de 2,43 para $5,10 \%$, podendo também ser devido ao maior conteúdo de leite (Tabela III).

\section{Granulometria}

Determinou-se a distribuição granulométrica do achocolatado de cupuaçu antes e após processamento por spray-dryer (Figuras 6 e 7) para se avaliar o comportamento das partículas com o processamento e verificar sua influência na instantaneização do produto.

TABELA III - Composição do produto tipo achocolatado normal antes e após processamento por spray-dryer (\% em $100 \mathrm{~g}$ do produto base seca)

\begin{tabular}{lccc}
\hline & Lipídios totais (\%) & Proteína (\%) & Cinzas (\%) \\
\hline antes do processamento & $8,27 \pm 0,090$ & $9,24 \pm 0,127$ & $2,43 \pm 0,050$ \\
após processamento & $3,22 \pm 0,040$ & $21,13 \pm 0,537$ & $5,10 \pm 0,046$ \\
\hline
\end{tabular}




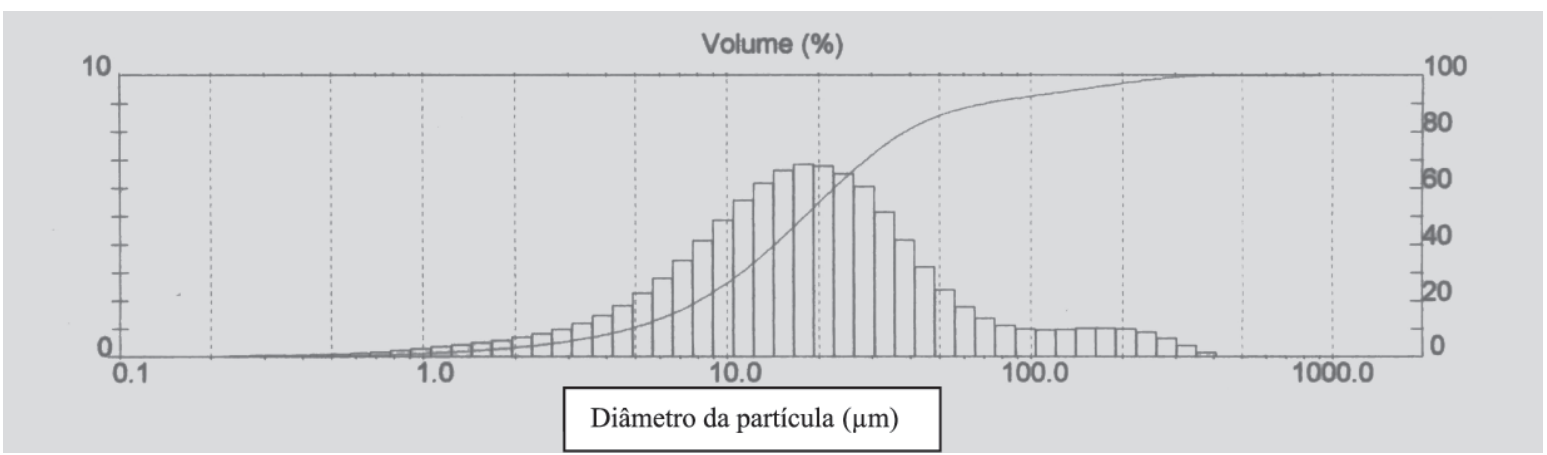

FIGURA 6 - Distribuição granulométrica do achocolatado antes da instantaneização.

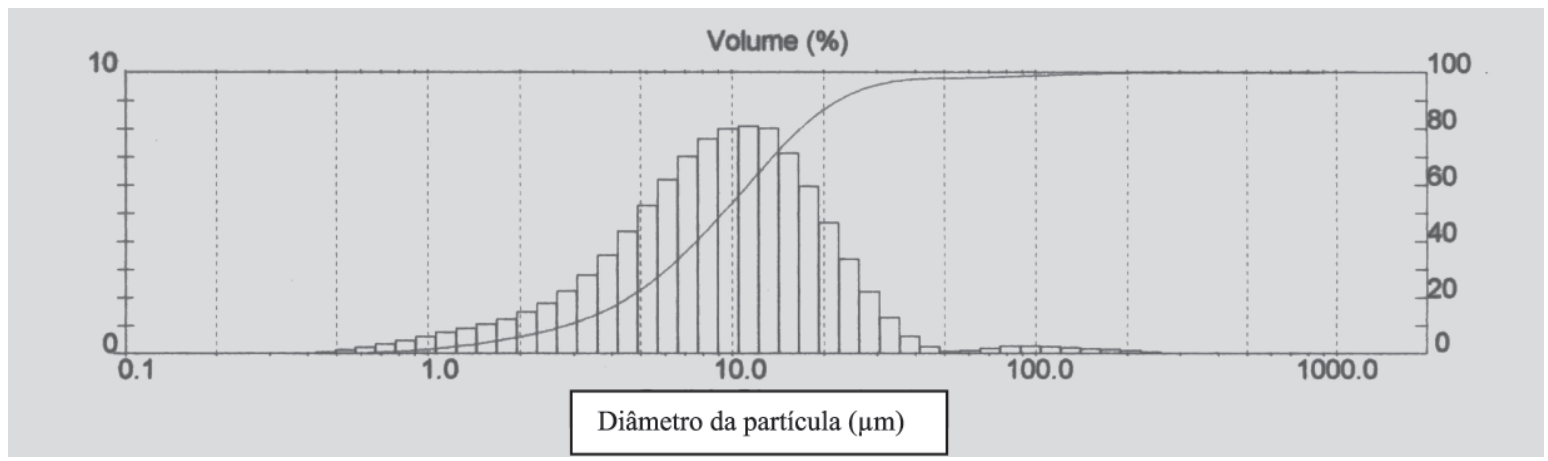

FIGURA 7 - Distribuição granulométrica do achocolatado após instantaneização.

Os resultados obtidos pela análise granulométrica mostram que antes e após ser processado no spray-dryer os produtos apresentavam-se conforme a Tabela IV.

Tabela IV - Diâmetros médios das partículas dos produtos antes e após o processamento por spray-dryer

\begin{tabular}{ccc}
\hline $\begin{array}{c}\text { Diâmetro } \\
\text { médio }\end{array}$ & $\begin{array}{c}\text { Produto antes do } \\
\text { processamento } \\
(\mu \mathrm{m})\end{array}$ & $\begin{array}{c}\text { Produto após o } \\
\text { processamento } \\
(\mu \mathrm{m})\end{array}$ \\
\hline $\mathrm{D}(\mathrm{v}, 0,1)$ & 4,75 & 2,80 \\
$\mathrm{D}(\mathrm{v}, 0,5)$ & 17,97 & 9,30 \\
$\mathrm{D}(\mathrm{v}, 0,9)$ & 70,65 & 22,37 \\
\hline
\end{tabular}

A dispersão de pó é afetada pela sua textura. Para obter propriedades de instantaneização, o pó deve possuir partículas com tamanhos próximos, sendo que partículas muito finas (poeira) devem ser evitadas (Cartwright, 1981). Isto pode ser explicado pela micronização que ocorre como um efeito da secagem por spray dryer, que é positiva na solubilidade e na regularidade do tamanho das partículas adquiridas (Manual, 1998).

Observa-se pelas Figuras 1 e 2 que houve diferença na distribuição granulométrica das partículas antes e após o processamento. Pela Tabela IV pode-se verificar a dimi- nuição do tamanho de partículas após o processamento, sendo que $90 \%$ das partículas encontraram-se com diâmetro de $22,37 \mathrm{~mm}$ e antes do processamento $90 \%$ com diâmetro $70,65 \mathrm{~mm}$, demonstrando a homogeneidade e a diminuição de tamanho das partículas, que ocorreu após o processamento, justificando a instantaneização do produto.

\section{Molhabilidade}

O teste de molhabilidade é utilizado pela indústria (Beddow, 1980). É um ensaio simples que fornece um parâmetro de tempo necessário para que o produto em pó seja absorvido pelo líquido. O teste efetuado demonstrou que o produto de cupuaçu em pó após spray-dryer possui maior poder molhante do que o produto antes do processo, levando metade do tempo para molhar. Embora o tempo máximo para o produto molhar seja uma escolha arbitrária, se $90 \%$ do produto mergulhar no líquido em $5 \mathrm{~min}$ pode ser um bom parâmetro. O nosso produto instantaneizado está abaixo deste limite.

\section{Adição de cálcio}

Os benefícios da celulose microcristalina em leite achocolatado fortificado podem ser resumidas em: propor- 
ciona maiores teores de cálcio, acima dos requerimentos da NLEA (Nutrition Labeling and Education Act), confere sensação sensorial suave e rica, contribui para as propriedades reológicas, permite a suspensão do cálcio e de outros nutrientes, baixa viscosidade (FMC).

A celulose microcristalina com cálcio foi adicionada a fim de se verificar a eficácia deste produto em formulações de achocolatado. Foi acrescentado após instantaneização, sendo que não houve problemas quanto à diluição em leite, nem em sabor ou outra característica do produto final.

\section{CONCLUSÕES}

- Nos resultados obtidos com relação ao processamento utilizando-se spray-dryer obteve-se rendimento de processo em torno de $20 \%$, uma vez que se observou a instantaneização do produto. Para o preparo de produtos em pó, não só alimentícios, mas, principalmente, os farmacêuticos, este processo mostra-se eficaz, sendo que o custo torna-se irrelevante dependendo da instalação industrial e do produto comercializado.

- Tanto o produto normal como o dietético tiveram comportamentos, físico, conforme previsão inicial do trabalho, e sensorial avaliados anteriormente por Medeiros e Lannes (2002).

\section{ABSTRACT}

\section{Cupuassu chocolate drink powder processed by spray-dryer}

Cupuassu chocolate drink powder is a mixture of cupuassu powder, sugar, flavour and other ingredients of formulation. The product was processed by spray-dryer, leading a dry, pulverized and instantised product. The chocolate drink powder with water (concentrated) pass through spray-dryer forming small diameter globules that are arrested by a hot air stream. The rapid evaporation allows keeping low temperature at drying air, and no affecting the product. The process is a set of better conditions of technique and economical efficiency in comparison to other process. Cupuassu powder does not disperse readily in water owing to its oil content. Consequently, a form of cocoa with the oil removed is needed to produce an acceptably instant drink. The results obtained were satisfactory, due to the complete instantisation of the product after processing.

UNITERMS: Cupuassu. Chocolate drink powder. Spraydryer. Instantisation.

\section{AGRADECIMENTOS}

À FAPESP-Fundação de Amparo à Pesquisa do Estado de São Paulo, pela verba de auxílio à pesquisa $\mathrm{e}$ pela bolsa de iniciação científica concedida aos autores.

Ao técnico do laboratório de Física Industrial, Gledson Manso Guimarães, pelo suporte técnico na operação do spray-dryer.

\section{REFERÊNCIAS BIBLIOGRÁFICAS}

AMAZONAS. Serviço de Apoio as Micros e Pequenas Empresas. Chocolate de cupuaçu: Programa de Informação. Manaus: SEBRAE, 1995. 52 p. (Série Perfis Empresariais).

BECKETT, S.T. Fabricación y utilización industrial del chocolate. Zaragoza: Acribia, 1994. 432 p.

BEDDOW, J.K. Testing and characterization of powders and fine particles. London: Heyden, 1980. 195p.

CARTWRIGHT, B. Spraying provides instant solutions. Food Flavour. Ingr. Pack. Process., v.3, n.8, p. 29-33, 1981.

ENGELHARD CLAYS. Formulation of persticidal dusts wettable powders and granules. New Jersey: Engelhard, s.d. $72 \mathrm{p}$.

FOLKENBERG, D. M.; BREDIE, W. L. P.; MARTENS, M. What is mouthfeel? Sensory-rheological relationship in instant hot cocoa drinks. J. Sensory Stud., Trumbull, v14, p.181-195, 1999 .

FMC - Application Bulletin. 180-7. s.n.t. 3 p. [Folheto].

GERHARDS, CH.; ULBRICHT, D. M.; PELEG, M. Mechanical characterization of individual instant coffee agglomerates. J. Food Sci., Chicago, v.63, n.1, 1998.

GUY, E. J.; VETTEL, H. E. A High quality protein, vitamin and mineral fortified chocolate-flavored for beverage use. J. Dairy Sci., Philadelphia, v.58, n.3, p.432, 1975.

HOUGH, G.; SÁNCHEZ, R. Descriptive analysis and external preference mapping of powdered chocolate milk. Food Qual. Prefer., v.9, n.4, p.197-204, 1998.

HOUGH, G.; SÁNCHEZ, R.; BARBIERI, T.; MARTINEZ, E. Sensory optimization of a powdered chocolate milk formula. Food Qual. Prefer., v.8, n.3, p.213-221, 1997. 
INSTITUTO ADOLFO LUTZ - Normas analíticas do Instituto Adolfo Lutz. 2.ed. São Paulo, 1976. v.1, p.14-63.

LINOYA, K.; GOTOH, K.; HIGASHITANI, K. Powder technology handbook. New York: Wiley, 1991. 794 p.

MANUAL de instruções do spray-dryer. s.1.: Büchi Labortechnik AG, 1997-1998. n.p.

LANNES, S. C. S.; MEDEIROS, M. L. Formulação de "chocolate" de cupuaçu e reologia do produto líquido. Rev. Bras. Cienc. Farm., São Paulo, v. 38, n. 4, p. 463469, 2002.

MASTERS, K. Spray drying handbook. 4.ed. London: Godwin, 1985. $696 \mathrm{p}$.

McCABE, W. L.; SMITH, J. C. Unit operations of chemical engineering . New York: McGraw-Hill, 1956. 945 p.

MEDEIROS, M. L.; LANNES, S. C. S. Torta de cupuaçu: composição e utilização. Rev. Bras.Ciênc. Farm., v.35, supl.1, p.118, 1999. [TBF53].

MEDEIROS, M. L.; LANNES, S. C. S. Avaliação sensorial de achocolatados de cupuaçu normal e dietético processados por spray-dryer. In: CONGRESSO BRASILEIRO DE CIÊNCIA E TECNOLOGIA DE ALIMENTOS, 18., Porto Alegre, 2002. Anais. Porto Alegre, SBCTA, 2002. p.1427-30. [CD-ROM]

MEDEIROS, M. L.; LANNES, S. C. S.; GIOIELLI, L. A. Gorduras de cacau e de cupuaçu: interações físicas. Rev. Bras.Cienc. Farm., v.35, supl.1, p.114, 1999. [TBF45].

NAZARÉ, R. F. R.; BARBOSA, W. C.; VIÉGAS, R. M. F. Processamento de sementes de cupuaçu para obtenção de cupulate. Bol. Pesquisa Embrapa, Belém, n.108, 38 p., 1990.

OHLMANN - 1 Labor-Wirbelschicht-GranulierProzessanlage. s.n.t. (FBE 1/3). n.p. [Folheto].

OMOBUWAJO, T. O.; BUSARI, O. T.; OSEMWEGIE, A. A. Thermal agglomeration of chocolate drink powder. $J$. Food Eng., London, v.46, p.73-81, 2000.
PERRY, R. H.; CHILTON, C. H. Manual de Engenharia Química. 5.ed. Rio de Janeiro:Guanabara Dois, 1980. n.p.

RHODES, M. J. Principles of powder technology. New York: Wiley, 1990. 439p.

SCHETTY, O.; ANKER, P.; JUNKER, E.; KLEINERT, J. Schokolade. In: Schweizerisches lebensmittelbuch. 5.ed. s.1.: s.n., 1969. v.3, p.47-51.

STRAATSMA, J.; VAN HOUWELINGEN, G.; STEENBERGEN, A. E.; DE JONG, P. Spray drying of food products: 1. Simulation model. J. Food Eng., London, v.42, p.67-72, 1999 (A).

STRAATSMA, J.; VAN HOUWELINGEN, G.; STEENBERGEN, A. E.; DE JONG, P. Spray drying of food products: 2. Prediction of insolubility index. J.Food Eng., London, v.42, p.73-77, 1999 (B).

VAN'T LAND, C. M. Industrial drying equipment. Selection and application. New York: Marcel Dekker, 1991.362 p.

VENTURIERI, G. A. Cupuaçu: a espécie, sua cultura, usos e processamento. Belém: Clube do cupu, 1993. 108 p.

VENTURIERI, G. A.; AGUIAR, J. P. L. Composição do chocolate caseiro de amêndoas de cupuaçu (Theobroma grandiflorum (WILLD EX SPRENG) SCHUM). Acta Amazonica, Manaus, v.18, n.1-2. p.3-8, 1988.

WENDEL, S.; CELIK, M. Uma visão geral sobre o uso da tenologia de spray-drying. Pharm. Technol., Ames, v.2, n.2, p.129-134, 1998.

WOLF, M. A. Accumulation of biomass and nutrients in the aboveground organs of four local tree species in monoculture and polyculture systems in central Amazonia. Braunschweig Braunschweig, 1997. n.p. [Diplom-thesis (unpubl.), Technische Universität Braunschweig].

Recebido para publicação em 12 de setembro de 2002. 